\title{
DOS OBSERVACIONES SOBRE EL EXEMPLO XI DE EL CONDE LUCANOR
}

Vilma Haydeé Arovich de Bogado

En el Exemplo XI de El Conde Lucanor se destaca el motivo del encantamiento puesto en acto por Don Illán, nigromante de Toledo, quien logra atrapar no sólo al personaje sino también al lector ${ }^{2}$. Podriamos afirmar que la magia trasciende al texto, envuelve al lector y lo incorpora a la ficción. Deseo hacer dos observaciones con respecto a esta instancia puntual.

\section{La instancia mágica en la concepción del creador}

I.1. La actualización del encantamiento en el discurso es un recurso introducido en la cadena intertextual por el Infante Dn. Juan Manuel ya que en las fuentes por él utilizadas sólo se enuncia, en algunos casos, que el maestro por medio de cierta magia / encantamiento / ilusión ${ }^{2}$ hace sentir al discípulo que ha ascendido en los estamentos eclesiásticos.

1.2. El encantamiento utilizado por el nigromante, más que un acto de hechicería, perteneceria al plano de la hipnosis o del ilusionismo. La cautela para tratar temas concernientes a lo mágico y a lo brujeril inscribe al texto en la linea de verosimilitud que nos llevará a Cervantes ${ }^{3}$. El resultado de esta actitud cautelosa es que consigue la credibilidad del relato.

1.3. De acuerdo con el Glosario en las Obras Completas de Don Juan Manuel ${ }^{4}$, nigromancia es el arte de adivinar el futuro ${ }^{5}$, no obstante, lo que Don Illán persigue y logra, sobre una supuesta proyección de futuro, es revelar la interioridad del hombre que tiene ante sí. Su finalidad es la de probar si el aspirante merece ser iniciado en la ciencia.

1.4. La puesta a prueba a la cual es sometido el deán está motivada por una buena intención que podemos explicitar de la siguiente manera: a. intenta cerciorarse de que el solicitante no engaña al nigromante ${ }^{6} ; b$. trata de verificar su lealtad; $c$. procura confirmar que no hará un uso indebido de la ciencia cuyo aprendizaje demanda. En suma, la intención es acreditar que puede transmitírsele el conocimiento.

De acuerdo con la legislación vigente en los tiempos manuelinos ${ }^{7}$ tal buena intención eximia de sanción al encantamiento, y por ende, de pena al encantador. 
1.5. De acuerdo con Santo Tomás, se denomina ciencia al conocimiento de las cosas humanas, en tanto que para el conocimiento de las cosas divinas se reserva el nombre de sabiduria". Para el Infante Don Juan Manuel el espiritu de sapiencia y el de ciencia son dos de los siete dones del Espiritu Santo y pertenecen a virtudes teologicas; la ciencia pertenece a la fe ${ }^{10}$ y la sapiencia a la caridad. Pero todas las sabidurias et todas las sciencias non son para otra cosa sinon porque a la fin de todo por las sciencias puede haber home le gloria del paraiso"

I.6. Don Juan Manuel no sólo establece la diferencia entre sabidurla y ciencia, sino que también considera que el saber debe ser aplicado a un buen fin et el saber en que ha algund mal o engaño non es verdadero saber, nin podrá facer buen fín quien de tal saber quisiere usar, ca es contra Dios que es verdadero saber et verdadera bondad ${ }^{22}$.

El concepto anteriormente transcripto mantiene vigente la imagen del sabio ejemplar y la del cientifico virtuoso ${ }^{13}$. Esta actitud virtuosa glorifica al sabio quien es consciente de que pervive en el tiempo a través de las enseñanzas que deja en los libros y que transmite a sus discipulos ${ }^{14}$.

1.7. De modo que, analizando el Exemplo XI en el nivel de la ideologia que subyace en el texto, y apoyándonos en el extratexto, podemos afirmar que para Don Juan Manuel, la ciencia deberia ser estudiada y usada sólo por el hombre virtuoso.

\section{La instancla mágica y la utilización de los recursos discursivos}

II.1.Más allá de que Don Juan Manuel esté inmerso en un contexto sociocultural marcado por la credulidad $^{16}$ en el cual la magia se ensenoreaba tanto en la vida cotidiana como en los testimonios literarios ${ }^{16}$, el encantamiento actuado en el Exemplo XI está determinado más por una intención didáctica y crítica ${ }^{17}$ que por un afán de pintoresquismo costumbrista ${ }^{18}$.

Il:2. El hombre usa la credulidad como materia de creación estética cuando é mismo ya la ha superado, ya no está sujeto a ella, en otras palabras, ya no cree ${ }^{19}$. Se ha senalado esta actitud como elemento determinante del nacimiento de la literatura fantástica moderna ${ }^{20}$; si adherimos a esta opinión, podrlamos señalar que el encantamiento al cual echa mano Don Juan Manuel en el Exemplo XI, lo anticipa a la modernidad; quizá por esta razón hoy lo continuamos considerando actual y conforme a la estética contemporánea ${ }^{21}$, a más de que fue reescrito por Jorge Luis Borges y por Enrique Anderson Imbert.

II.3. Maria Rosa Lida ${ }^{22}$ ubica este cuento en el grupo de los que muestran visiones del trasmundo a raíz de dos indicios: el descenso tan profundo 
que se sugiere que el río Tajo pasa por encima de los protagonistas, y la concepción del tiempo dilatado. Ambos ocurren en el fragmento delimitado por el motivo de las perdices, hito que marca ef límite (al concluir el relato lo sabemos) entre el mundo real y el de la ilusión ${ }^{23}$.

La orden verbal de preparar las perdices configuraría la fórmula mágica que haría las veces de disparador hacia lo ilusorio, plano en el cual el nigromante alcanzará el objeto deseado que es la revelación de la interioridad del visitante. Bousono 24 señala en el hombre primitivo una tendencia simbolizante que identifica la palabra (nombre, fórmula mágica) con el objeto; pronunciar uno significa poseer lo otro. Lo que me interesa destacar es que en el encantamiento al cual estamos refiriéndonos, el único medio o recurso del cual se vale el nigromante es la palabra ${ }^{28}$.

11.4. Una vez enmarcada la secuencia del encantamiento con el motivo de las perdices, en su desarrollo puede el autor incorporar los más extraños incidentes, dispararnos en el tiempo y en el espacio, sin quebrar la norma de la verosimilitud.

Tal lo que ocurre con el tiempo que se dilata (para emplear la expresión de Marla Rosa Lida ${ }^{20}$ ) en un lapso de anos, y se desarrolla en un espacio ilusorio que nos aleja progresivamente de Toledo (Santiago- Tolosa- la corte/ Roma/ ) y describiendo un itinerario circular regresa a Toledo y al encuentro inicial de los protagonistas.

\section{A modo de conclusión}

Podriamos sefialar dos movimientos sucesivos y contrapuestos:

a. El primero de ellos registra un sentido vertical de descenso hacia las más oscuras profundidades del espacio subterráneo simbólico de las profundidades de la conciencia en las cuales hurga el nigromante. Este movimiento es el que crea la atmósfera.

b. El otro, es el movimiento a través del cual se va desenvoviendo la secuencia ilusoria, que describe un itinerario circular y que va sacando a la luz la respuesta buscada por el mago.

Ambos movimientos convergen en la figura del deán y su mágica combinación tiene por objeto simplemente constatar si el personaje es digno de recibir el bagaje de conocimientos que puede transmitir el nigromante.

Simultáneamente a los movimientos espaciales contrapuestos creo advertir una linea de acción - reacción entre los protagonistas a partir de la 
actuación de Don Illán; el resorte que desencadena la secuencia ilusoria es el temor que tiene el mago de ser engañado por el deán; pero tanta aprehensión, finalmente lo coloca a él como engañador.

Tan alto es el concepto en que Don Juan Manuel tiene a la ciencia y tanto es el recelo de ser engañado, que tal vez piense que las artes ilusorias son el único medio que puede darnos una pista confiable en esta ardua tarea de conocer verdaderamente al otro, más aún, cuando este conocimiento acreditará si merece o no que le confiemos bienes que en tanta estima tenemos.

\section{CITAS Y NOTAS}

${ }^{1}$ Ya María Rosa Lida de Malkiel señala este ilusionismo sutil que engaña al personaje y al lector (Lida Estudios p.110).

${ }^{2}$ Transcriptas en Ay. Chaux Conde ps. 239-243.

${ }^{3}$ Véase Riley Teoría cap. V especialmente ps. 296-297.

4 J.Manuel Obras II p. 858.

${ }^{5}$ Flores Arroyuelo da otra definición relacionada con la actividad de reanimar cadáveres (Flores Diablo p. 15); en cambio Huerta Tejadas la identifica sólo como magia negra (H.Tejadas Vocabulario p. 86). Kieckhefer indica como propósitos de la nigromancia la creación de ilusiones y la averiguación de secretos (Kieckhefeler Magia p.170)

'Es preocupación de Don Juan Manuel precaverse del engaño de los demás: guardatvos de beguineria et hipocresia (J.Manuel Infinido p. 266).

${ }^{7}$ Las Partidas de Alfonso El Sabio por ejemplo. (Mz. Pelayo Heterodoxos cap. VII ps. 311-312.)

${ }^{8}$ Sto. Tomás Fe cuestión 9 art. 2.

'J. Manuel Predicadores p.365.

${ }^{10}$ Sto. Tomás A la fe le corresponde el don del entendimiento y no el de la ciencia Fe cap.9 art.1.

11 J.Manuel Predicadores p.366.

12 J. Manuel Infinido ps.264-265.

${ }^{13}$ Maravall Saber p.218.

${ }^{14}$ Bizarri Omnis p. 177. 
${ }^{16}$ A. Imbert Cuento p. 251.

${ }^{16}$ Russell Magia p.254.

${ }^{17}$ Emilio Carilla sefiala la intención claramente moral de los episodios fantásticos (Carilla Cuento p.64).

${ }^{18}$ Giordano Religiosidad p.183.

${ }^{19} \mathrm{La}$ incredulidad de Don J. Manuel se refleja en el Exemplo XXXII "De lo que contesçio a un rey con los burladores que fizieron un panno" y en el Exemplo XX "De lo que contesçio a un rey con un omne quel dixo quel faria alquimia" en los cuales la magia se muestra sólo como astucia de embaucadores (Mz. Pelayo Heterodoxos cap. VII p.317).

${ }^{20}$ A. Imbert Cuento p.245.

21 Ay. Chaux Conde p.98.

${ }^{22}$ Lida Visión p.379.

${ }^{23}$ Carilla señala este procedimiento de Don Juan Manuel como antecedente de la técnica utilizada por Borges en El milagro secreto (Carilla Cuento ps. 45-46).

${ }^{24}$ Bousoño Épocas II ps. 407-414.

${ }^{26}$ Jorge Luis Borges seffala para la novela un proceso causal mágico similar al que se produce en la mente del supersticioso: Ese recelo de que un hecho temible purda ser atraido por su mención, es impertinente o inútil en el asiático desorden del mundo real, no asi en una novela... (Borges Arte p.231).

${ }^{26}$ Véase cita 22.

\section{ABREVIATURAS BIBLIOGRÁFICAS}

A. Imbert Cuento = Enrique Anderson Imbert Teoría y Técnica del cuento (Bs. As.: De. Marymar, 1979).

Ay. Chaux Conde $=$ Reinaldo Ayerbe Chaux El Conde Lucanor. Materia tradicional y originalidad creadora (Madrid: Ed. José Porrúa Turanzas, 1975).

Bizarri Omnis = Hugo Oscar Bizarri “" Non omnis moriar' Sobre la fama del Sabio en la Edad Media Castellana" Thesaurus XLV (1990) ps.174-179.

Borges Arte $=$ Jorge Luis Borges El arte narrativo y la magia Obras Completas (1923- 1972) (Bs. As.: Emecé Editores, 1974).

Bousoño Epocas = Carlos Bousoño Epocas literarias y evolución 2 vol. (Madrid: Gredos, 1981).

Carilla Cuento $=$ Emilia Carilla El cuento fantástico (Bs. As.: Nova, 1968). 
Flores Diablo = Francisco J. Flores Arroyuelo El Diablo en Esparia (Madrid: Alianza Ed., 1985).

Giordano Religiosidad = Oronzo Giordano La religiosidad popular en la Edad Media (Madrid: Gredos, 1983).

H. Tejadas Vocabulario = Félix Huerta Tejadas Vocabulario de las Obras de Don Juan Manuel (1282- 1348). B.R.A.E. XXXV/CXLIV (1955) ps. 85-132.

J.Manuel "Infinido" = El libro de los Castigos o Consejos que fizo Don Johan Manuel para su fijo, et es llamado por otro nombre El Libro Infinido.Escritores en prosa anteriores al siglo XV (Madrid: B.A.E., LI, 1952).

J.Manuel Obras = Don Juan Manuel Obras Completas. Ed., prólogo y notas de José Manuel Blecua (Madrid: Gredos, 1983).

J.Manuel Predicadores $=$ Don Juan Manuel Libro de los fraires predicadores. Escritores en prosa anterioresal siglo XV (Madrid: B.A.E., LI, 1952).

Kieckhefer Magia = Richard Kieckhefer La magia en la Edad Media (Barcelona : Crítica, 1992)

Lida Estudios = Maria Rosa Lida de Malkiel Tres notas sobre Don Juan Manuel Estudios de Literatura Española y Comparada (Bs.As.:EUDEBA, 1966).

Lida Visión = Maria Rosa Lida de Malkiel La visión del transmundo en las literaturas hispánicas Apéndice de Howard

Rollin Patch El otro mundo en la literatura medieval (México:F.C.E., 1983).

Maravall Saber $=$ José Antonio Maravall La concepción del saber en una sociedad tradicional Estudio de Historia del Pensamiento Español (Madrid: Ed. Cultura Hispánica, 1967).

Mz. Pelayo Heterodoxos = Marcelino Menéndez y Pelayo Historia de los heterodoxos españoles III en Obras Completas (Bs. As.: Espasa Calpe, 1931)

Riley Teoria = Edward Riley Teoría de la novela en Cervantes (Madrid: Taurus, 1971).

Russell Magia = Peter E. Russell La magia, tema integral de la Celestina Temas de La Celestina (Barcelona: Ariel, 1978).

Sto. Tomás $\mathrm{Fe}=$ Tomás de Aquino Tratado de la Fe Suma de Teologia III (Biblioteca de Autores Cristianos, 1990). 